\title{
Apnoea-hypopnoea-index comparing the 2007 and 2012 American Academy of Sleep Medicine criteria in chronic obstructive pulmonary disease/obstructive sleep apnoea overlap syndrome
}

\author{
Baiting $\mathrm{He}^{1,2,3}$, Miral Al-Sherif ${ }^{1,2,4}$, Yingxin $\mathrm{Wu}^{3}$, Sean Higgins ${ }^{1}$, Esther Irene Schwarz ${ }^{1,5}$, Yuanming Luo ${ }^{2,3}$, \\ Azza Farag Said ${ }^{4}$, Nezar Refat ${ }^{4}$, Nashwa Hassan Abdel Wahab ${ }^{6}$, Joerg Steier ${ }^{1,2}$ \\ ${ }^{1}$ Lane Fox Unit/Sleep Disorders Centre, Guy's \& St Thomas' NHS Foundation Trust, London, UK; ${ }^{2}$ King's College London, Faculty of Life \\ sciences and Medicine, Centre of Human and Applied Physiological Sciences (CHAPS), UK; ${ }^{3}$ Key National Laboratory for Respiratory Disease, \\ Guangzhou Medical University, Guangzhou, China; ${ }^{4}$ Department of Respiratory Medicine, Minia University, Menia, Egypt; ${ }^{5}$ Department of \\ Pulmonology and Sleep Disorders Centre, University Hospital Zurich, Zurich, Switzerland; 'Department of Respiratory Medicine, Alexandria \\ University, Alexandria, Egypt \\ Contributions: (I) Conception and design: B He, J Steier; (II) Administrative support: None; (III) Provision of study materials or patients: None; (IV) \\ Collection and assembly of data: None; (V) Data analysis and interpretation: B He, M Al-Sherif, Y Wu, S Higgins; (VI) Manuscript writing: All \\ authors; (VII) Final approval of manuscript: All authors. \\ Correspondence to: Professor Joerg Steier, FRCP, MD, PhD. Guy's \& St Thomas' NHS Foundation Trust, King's College London, Westminster \\ Bridge Road, London SE1 7EH, UK. Email: Joerg.steier@gstt.nhs.uk.
}

Background: In 2007 and 2012, the American Academy of Sleep Medicine (AASM) updated their scoring criteria for nocturnal respiratory events. We hypothesised that this could have led to changes in the apnoeahypopnoea index (AHI) of patients with chronic obstructive pulmonary disease (COPD)/obstructive sleep apnoea (OSA) overlap syndrome.

Methods: In a retrospective study, polysomnographic (PSG) recordings of 34 patients with COPD/OSA overlap syndrome were independently analysed using the AASM criteria from $2007\left(\mathrm{AASM}_{2007}\right)$ and 2012 $\left(\mathrm{AASM}_{2012}\right)$. The primary outcome was the difference in AHI, the secondary outcomes were frequency of hypopnoeas, diagnosis of overlap syndrome and differences between the AASM 2007 recommended $\left(\mathrm{AASM}_{2007 \mathrm{Rec}}\right)$ and altered (AASM $\left.\mathrm{A007Alt}_{\text {Alt }}\right)$ classifications. Data are presented as mean (standard deviation) if normally distributed, and as median (interquartile range) if non-normally distributed.

Results: The PSGs of 34 elderly [aged 67 (7.0) years] and predominantly male (m:f, 31:3) patients with COPD $\left[\mathrm{FEV}_{1} \%\right.$ pred 48.4\% (19.6\%)] were analysed. The AHI using $\mathrm{AASM}_{2007 \operatorname{Rec}}$ criteria was $5.9(2.0,15.1)$ events/hour vs. $20.4(11.5,28.0)$ events/hour using the 2012 criteria $(\mathrm{P}<0.001)$; with the $\mathrm{AASM}_{2007 \mathrm{Alt}}$ criteria, the AHI was $15.0(9.3,26.3)$ events/hour $(\mathrm{P}<0.001)$. Using the 2012 classification, the number of scored hypopnoeas increased by $+48 \%$ compared to the $\mathrm{AASM}_{2007 \mathrm{Rec}}$ criteria $(\mathrm{P}<0.001), 92 \%$ of these events were associated with arousal. Although statistically non-significant, using the $\mathrm{AASM}_{2007 \mathrm{Alt}}$ classification, $12 \%$ of our cohort would not have been diagnosed with COPD/OSA overlap syndrome $(\mathrm{P}=0.114)$, this was also the case for $47 \%$ of the cohort when the $\mathrm{AASM}_{2007 \mathrm{Rec}}$ classification was used $(\mathrm{P}<0.01)$.

Conclusions: The use of the $\mathrm{AASM}_{2012}$ scoring rules results in a significantly higher AHI compared to the $\mathrm{AASM}_{2007}$ criteria in patients with COPD/OSA overlap syndrome, mostly due to an increased number of arousal-associated hypopnoeas. These observations are important for the definition of the COPD/OSA overlap syndrome.

Keywords: Polysomnography; classification; hypopnoea; arousal; desaturation

Submitted May 15, 2020. Accepted for publication Jul 27, 2020.

doi: 10.21037/jtd-cus-2020-008

View this article at: http://dx.doi.org/10.21037/jtd-cus-2020-008 


\section{Introduction}

Sleep-disordered breathing is a common problem in the general population, the most common form of which is obstructive sleep apnoea (OSA) $(1,2)$. In addition, chronic obstructive pulmonary disease (COPD) affects more than 250 million people according to a recent report (3). A high prevalence of the combination of both COPD and OSA has been reported since its description as "overlap syndrome" by Flenley in $1985(4,5)$.

The apnoea-hypopnoea index (AHI) is a key component in the diagnosis, the classification of severity and the assessment of any treatment response of sleep-disordered breathing, in particular of OSA (6). However, the criteria for scoring apnoeas and hypopnoeas, which are required to calculate the AHI, have recently changed, particularly for hypopnoea events (7).

In 2007, the American Academy of Sleep Medicine (AASM) published the manual for the scoring of sleep and associated events mostly adopted in clinical practice, which included "recommended" $\left(\mathrm{AASM}_{2007 \mathrm{Rec}}\right)$ and "alternative" $\left(\mathrm{AASM}_{2007 \mathrm{Alt}}\right)$ scoring criteria (8). The hypopnoea definitions of $\mathrm{AASM}_{2007 \mathrm{Rec}}$ require a reduction of $30 \%$ or more in the nasal pressure signal, associated with a $\geq 4 \%$ desaturation, and those of $\mathrm{AASM}_{2007 \mathrm{Alt}}$ require a $50 \%$ or more reduction in nasal pressure signal associated with a $\geq 3 \%$ desaturation or an arousal. With the objective of improvement, the AASM published an update of the 2007 manual in 2012 (known as the $\mathrm{AASM}_{2012}$ Manual), particularly considering the implications for lean people and OSA associated outcomes (7). The AASM 2012 criteria recommendations define the scoring criteria for a hypopnoea in case of a $\geq 30 \%$ reduction in nasal pressure flow associated with a $\geq 3 \%$ desaturation or an arousal.

Since then, several studies have assessed the impact of different hypopnoea definitions on the AHI and diagnosis of OSA in the general population $(9,10)$. BaHammam et al. demonstrated that the $\mathrm{AASM}_{2012}$ criteria could lead to a higher AHI when compared to the $\mathrm{AASM}_{2007}$ criteria (10). Recently, Duce et al. further confirmed that the AASM 2012 criteria were generally associated with higher AHIs than the 2007 criteria, but led to similar AHI and diagnostic outcomes as the 1999 manual (9). In a large populationbased study using home polysomnography (PSG) in more than 2,000 people, applying different scoring rules for hypopnoea resulted in a large difference in the prevalence of OSA and a twofold difference in an AHI threshold associated with hypertension (11).
However, there are no studies to report the impact of the changed classification on the AHI and diagnosis of OSA in patients with COPD, the COPD/OSA overlap syndrome. Generally, COPD patients with severe emphysema may be more likely to be lean and elder than the general population and, due to a lower oxygen saturation and hypoventilation, more prone to frequent nocturnal oxygen desaturations. Thus, we hypothesised that the $\mathrm{AASM}_{2012}$ criteria could have led to significant changes in the AHI and the diagnosis of patients with COPD associated OSA due to a change in the definition of hypopnoea. We present the following article/case in accordance with the STROBE reporting checklist (available at http://dx.doi.org/10.21037/jtdcus-2020-008).

\section{Methods}

This was a retrospective study preformed in the Sleep Disorders Centre at Guy's \& St Thomas' NHS Foundation Trust, King's College London, UK and the First Affiliated Hospital of Guangzhou Medical University. All consecutive stable patients diagnosed with COPD by respiratory specialists (post-bronchodilator $\mathrm{FEV}_{1} / \mathrm{FVC}$ ratio of $<0.7$ ) and OSA (AHI $\geq 5$ events/hour in an overnight PSG) between August 2013 and April 2019 were eligible. In the British cohort, all patients with COPD/OSA Overlap Syndrome who underwent PSG between August 2013 and April 2019 were screened, but in the Chinese cohort, the first 26 patients screened backwards were selected. To ensure a reliable analysis, patients were not included if any primary PSG channel (nasal pressure, pulse oximetry, all EEG, respiratory effort) contained artefacts during more than $30 \%$ of total sleep time, or the total sleep time was too short ( $<2.8$ hours). This study was approved by the review board of Guy's \& St Thomas' NHS Foundation Trust of King's College London and the First Affiliated Hospital of Guangzhou Medical University (the registered service review: 2019/9662). This retrospective study was conducted in accordance with the Declaration of Helsinki (as revised in 2013). The requirement for informed consent was waived because of the retrospective study design. All eligible patients were reviewed by a respiratory consultant through the 'electronic patient record' system to obtain basic information such as age, body mass index (BMI), spirometry (forced expiratory volume in $1 \mathrm{~s}\left(\mathrm{FEV}_{1}\right)$, forced vital capacity (FVC) and the ratio of $\mathrm{FEV}_{1}$ to $\mathrm{FVC}\left(\mathrm{FEV}_{1} /\right.$ FVC)) and Epworth sleepiness scale (ESS). The PSG data of all eligible patients were re-analysed by experienced sleep 
technicians.

\section{Outcome parameters}

The primary outcome of this retrospective study was the difference in AHI using 2007 vs. 2012 criteria. Secondary outcomes were frequency of hypopnoeas, diagnosis of overlap syndrome, and differences between the AASM 2007 recommended $\left(\mathrm{AASM}_{2007 \mathrm{Rec}}\right)$ and altered $\left(\mathrm{AASM}_{2007 \mathrm{Al}}\right)$ classifications.

\section{Polysomnography recording and scoring}

Inpatient PSGs were recorded in the sleep laboratory using Rembrandt polysomnography system (Embla, Broomfield, CO, USA) in the UK, and Alice 5 diagnostic equipment (Respironics Inc., Murrysville, PA, USA) in China. The recording montage consisted of EEG (F3A2, F4A1, C3A2, C4A1, O1A2, O2A1), eye movements (E1M2 \& E2M1), muscle tone (electromyogram of chin and both legs), oxygen saturation (finger pulse oximeter), chest and abdominal wall movement (thoracic and abdominal inductance plethysmography), airflow (thermistor and nasal pressure transducer), and snoring (microphone). Sleep stages and arousals of the British cohort $(n=8)$ and the Chinese cohort $(n=26)$ were analyzed by a trained PSG scorer (UK: SH, China: YXW). These PSGs were randomly assigned to three PSG scorers (BTH, MS, YXW) to be re-analysed for respiratory events. Respiratory events were independently reanalysed three times in random order, and scored using either the $\mathrm{AASM}_{2007 \mathrm{Rec}}$, $\mathrm{AASM}_{2007 \mathrm{Alt}}$ or $\mathrm{AASM}_{2012}$ criteria. The hypopnoea definitions of $\mathrm{AASM}_{2007 \mathrm{Rec}}$ require a reduction of $30 \%$ or more in the nasal pressure signal, associated with a $\geq 4 \%$ oxygen desaturation, and those of $\mathrm{AASM}_{2007 \mathrm{Alt}}$ require a $\geq 50 \%$ reduction in nasal pressure signal associated with a $\geq 3 \%$ desaturation or an arousal (8). The $\mathrm{AASM}_{2012}$ criteria recommendations define the scoring criteria for a hypopnoea as a $\geq 30 \%$ reduction in nasal pressure flow associated with a $\geq 3 \%$ desaturation or an arousal (7).

\section{Statistical analysis}

Statistical analysis was performed using SPSS 16.0 (Chicago, IL/USA) following collection of the data in MS Excel 2010 (Microsoft, Seattle, WA/USA). The data are presented as mean [standard deviation (SD)] if normally distributed, and as median [interquartile range (IQR)] if non-normally distributed. Group data were compared using the paired $t$-test or the Friedman test, with the Tukey's honestly significant difference (HSD) post hoc test for multiple comparisons. The diagnosis of OSA and severity of disease in the patient cohort, as defined by using the different scoring criteria, were compared using the Chi-Square test. The agreement of the different criteria was further compared using Bland-Altman plots. Stepwise multiple linear regression analysis was performed to investigate predictors of the AHI (2012 vs. 2007Alt, 2012 vs. 2007Rec) including age, gender, BMI, and severity of COPD. In all analyses, a $\mathrm{P}<0.05$ was considered statistically significant.

\section{Results}

\section{Patient characteristics}

Seven patients' PSGs were excluded due to bad signals of PSGs $(n=4)$ and the lack of spirometry result $(n=3)$. Thirtyfour patients were included in the analysis. A summary of patient's characteristics and PSG results are presented in Table 1 . The 26 patients from China were older $(69 \pm 5 \mathrm{vs}$. $61 \pm 10$ years, $\mathrm{P}<0.01$ ) and leaner (BMI, $20 \pm 3 v s .33 \pm 9 \mathrm{~kg} / \mathrm{m}^{2}$, $\mathrm{P}<0.001)$, and had more severe airway obstruction $\left(\mathrm{FEV}_{1}\right.$ $\%$ pred, $45 \% \pm 14 \%$ vs. $60 \% \pm 30 \%, \mathrm{P}=0.046$ ) than the eight patients from the UK.

\section{Differences in AHI and bypopnoea-index (HI) according to scoring criteria}

The AHI and HI were significantly different between $\mathrm{AASM}_{2012}$ criteria, AASM $2007 \mathrm{Alt}$ and $\mathrm{AASM}_{2007 \mathrm{Rec}}(\mathrm{P}<0.001$; Table 2). The $\mathrm{AASM}_{2012}$ criteria resulted in an increase in the AHI of $12 \%(9 \%, 26 \%)$ and $64 \%(38 \%, 86 \%)$ compared to $\mathrm{AASM}_{2007 \mathrm{Alt}}$ and $\mathrm{AASM}_{2007 \mathrm{Rec}}$, respectively. Bland-Altman analyses for $\mathrm{AHI}_{2012}, \mathrm{AHI}_{2007 \mathrm{Alt}}$ and $\mathrm{AHI}_{2007 \mathrm{Rec}}$ showed a bias of 3.5 (95\% CI, -2.0 to 8.9 ) events/hour and 11.7 (95\% CI, -1.0 to 24.4) events/hour in the $\mathrm{AASM}_{2012}$ criteria when compared to $\mathrm{AASM}_{2007 \mathrm{Alt}}$ and $\mathrm{AASM}_{2007 \mathrm{Rec}}$, respectively (Figure 1). There was an increase of $25 \%$ in the number of hypopnoeas scored by the $\mathrm{AASM}_{2012}$ criteria when compared to $\mathrm{AASM}_{2007 \mathrm{Alt}}(\mathrm{P}<0.001)$ due to the change of rules from $\geq 50 \%$ to $\geq 30 \%$ flow reduction. The $\mathrm{AASM}_{2012}$ criteria resulted in an increase in the number of hypopnoeas events of $48 \%$ compared to the $\mathrm{AASM}_{2007 \mathrm{Rec}}$ criteria $(\mathrm{P}<0.001) ; 92 \%$ of these events were associated with arousal. 


\section{OSA diagnosis}

Using the $\mathrm{AASM}_{2007 \mathrm{Rec}}$ classification, $48 \%$ of the $\mathrm{AASM}_{2012}$ overlap syndrome cohort would not have been diagnosed with COPD/OSA overlap syndrome if using the diagnostic criteria of an $\mathrm{AHI} \geq 5$ events/hour $(\mathrm{P}<0.01)$; this was also the case for $12 \%$ of the cohort when the $\mathrm{AASM}_{2007 \mathrm{Alt}}$

Table 1 Summary of demography, spirometry and polysomnography result

\begin{tabular}{|c|c|}
\hline Parameter & Mean \pm SD \\
\hline $\mathrm{n}$ & 34 \\
\hline Age (years) & $67.0 \pm 7.0$ \\
\hline Sex $M / F$ & $31 / 3$ \\
\hline Body mass index $\left(\mathrm{kg} / \mathrm{m}^{2}\right)$ & $23.0 \pm 6.9$ \\
\hline $\mathrm{FEV}_{1}(\%$ pred) & $48.4 \pm 19.6$ \\
\hline $\mathrm{FEV}_{1} / \mathrm{FVC}(\%)$ & $49.5 \pm 12.7$ \\
\hline ESS (points) & $8.0 \pm 5.4$ \\
\hline Total sleep time (h) & $4.7 \pm 1.1$ \\
\hline Sleep efficiency (\%) & $57.2 \pm 14.5$ \\
\hline Stage N1 (\%) & $31.1 \pm 16.5$ \\
\hline Stage N2 (\%) & $44.1 \pm 16.2$ \\
\hline Stage N3 (\%) & $8.2 \pm 13.4$ \\
\hline Stage R (\%) & $16.5 \pm 6.9$ \\
\hline Al (events/h) & $23.5 \pm 9.7$ \\
\hline $4 \%$ ODI (events/h) & $12.0 \pm 15.3$ \\
\hline Wake $\mathrm{SpO}_{2}(\%)$ & $94.7 \pm 1.7$ \\
\hline Mean $\mathrm{SpO}_{2}(\%)$ & $94.0 \pm 2.3$ \\
\hline Nadir $\mathrm{SpO}_{2}(\%)$ & $86.4 \pm 5.6$ \\
\hline Time with $\mathrm{SpO}_{2}<90 \%$ (min) & $21.8 \pm 37.9$ \\
\hline$\%$ of TST with $\mathrm{SpO}_{2}<90 \%$ (\%) & $6.7 \pm 11.1$ \\
\hline
\end{tabular}

SD, standard deviation; ESS, Epworth Sleepiness Scale; FEV ${ }_{1}$, forced expiratory volume in 1 second; FVC, forced vital capacity; $\mathrm{Al}$, arousal index; ODI, oxygen desaturation index.
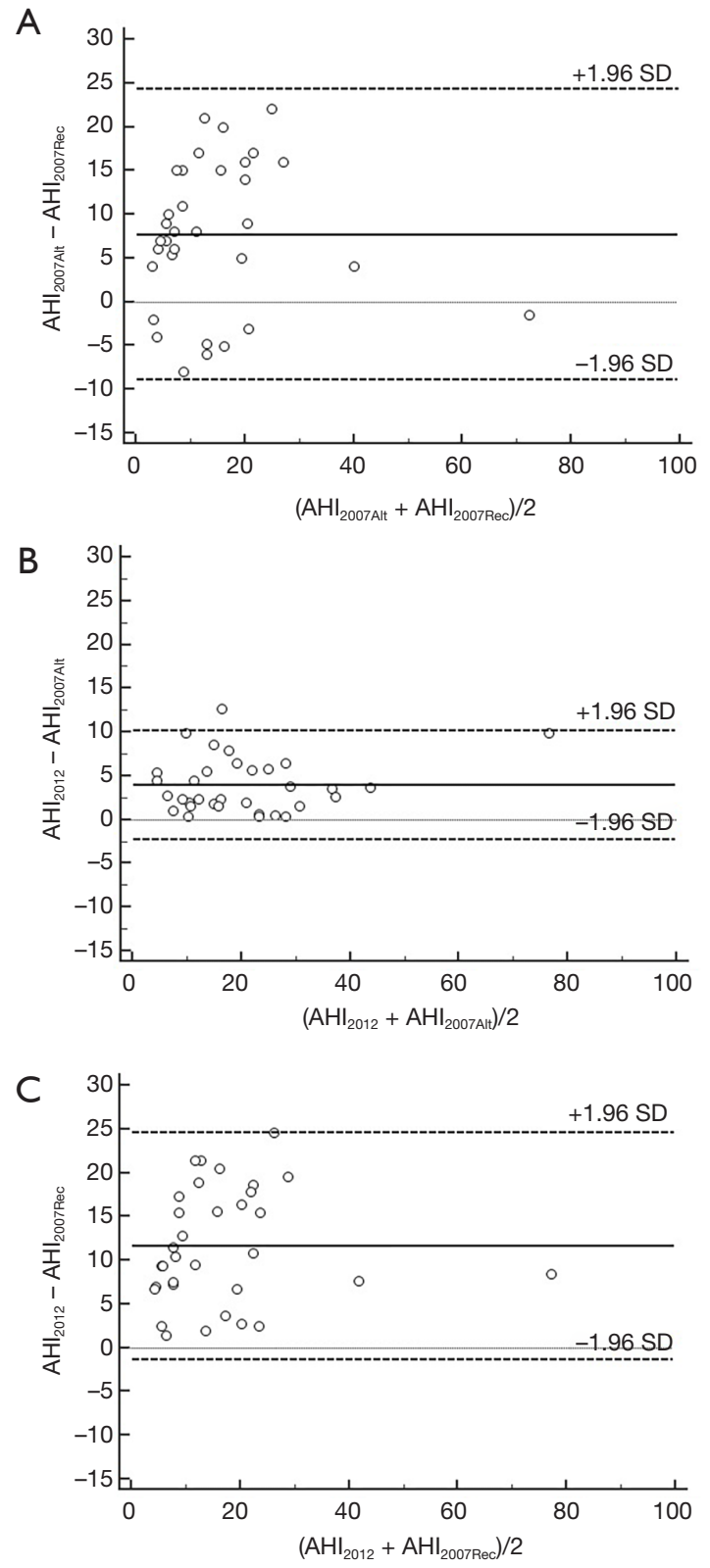

Figure 1 Bland-Altman agreement plots. The thick line represents the mean difference. The dashed lines represent \pm 1.96 standard deviation.

Table 2 AHI and HI using the $\mathrm{AASM}_{2012}, \mathrm{AASM}_{2007 \mathrm{Alt}}$, or $\mathrm{AASM}_{2007 \mathrm{Rec}}$ criteria

\begin{tabular}{|c|c|c|c|c|}
\hline Parameter & AASM2012 & AASM2007Alt & AASM2007Rec & $P$ \\
\hline HI (events/hour) & $16.1(10.1,21.3)$ & $11.8(8.0,17.9)$ & $2.4(0.68,6.9)$ & $<0.001$ \\
\hline
\end{tabular}

Data were presented as median (interquartile range). AASM, American Academy of Sleep Medicine; AHI, apnoea-hypopnoea index; HI, hypopnoea index. 
Table 3 Patient diagnosis according to hypopnoea criteria

\begin{tabular}{lccc}
\hline Diagnosis & AASM2012 & AASM2007Alt & AASM2007Rec \\
\hline No OSA & 0 & $4(11.8 \%)$ & $16(47.1 \%)^{*}$ \\
Mild OSA & $12(35.3 \%)$ & $13(38.2 \%)$ & $9(26.5 \%)$ \\
Moderate OSA & $15(44.1 \%)$ & $12(35.3 \%)$ & $7(20.6 \%)^{*}$ \\
Severe OSA & $7(20.6 \%)$ & $5(14.7 \%)$ & $2(5.9 \%)$ \\
\hline
\end{tabular}

Values presented as absolute number of diagnoses (\% of total number of patients). ${ }^{*}, \mathrm{P}<0.05$ compared to AASM2012. AASM, American Academy of Sleep Medicine; OSA, obstructive sleep apnoea.

Table 4 Stepwise multiple linear regression analysis of the discrepancy in the AHI (2012 vs. 2007Alt, 2012 vs. 2007Rec) (n=33)

\begin{tabular}{|c|c|c|c|c|c|c|}
\hline Dependent variable & $\begin{array}{l}\text { Statistically significant } \\
\text { independent variables }\end{array}$ & B & SE B & $P$ value & $\begin{array}{c}\text { Non-significant } \\
\text { independent variables }\end{array}$ & $P$ value \\
\hline \multirow[t]{2}{*}{$\triangle \mathrm{AH}$ 2012-2007Alt } & BMI & 0.190 & 0.054 & 0.001 & Age & 0.179 \\
\hline & Severity of COPD & -1.356 & 0.530 & 0.016 & & \\
\hline$\triangle \mathrm{AH} \mathrm{I}_{2012-2007 \mathrm{Rec}}$ & BMI & -0.362 & 0.138 & 0.013 & Age & 0.781 \\
\hline
\end{tabular}

$\mathrm{B}$, the standardized regression coefficient; $\mathrm{SE} \mathrm{B}$, the standard error of beta; $\triangle \mathrm{AHI}_{2012-2007 \mathrm{Alt}}$, the discrepancy in the $\mathrm{AHI}$ between the 2012 criteria and the 2007Alt criteria; $\triangle \mathrm{AHI}_{2012-2007 R e c}$, the discrepancy in the AHI between the 2012 criteria and the 2007Rec criteria; severity of COPD, classification by post-bronchodilator spirometry (1: $\mathrm{FEV}_{1} \%$ pred $\geq 80 \%$; 2 : FEV 1 \%pred $50 \%$ to $79 \%$; 3 : FEV 1 \%pred $30 \%$ to $49 \%$; 4 : $\mathrm{FEV}_{1}$ \%pred <30\%); AHI, apnoea-hypopnoea index; BMI, body mass index; COPD, chronic obstructive pulmonary disease.

classification was used $(\mathrm{P}=0.114)$. Moreover, $38 \%$ of our cohort were above the threshold for moderate OSA with an AHI of 15 events/hour using the $\mathrm{AASM}_{2012}$, but not when using the $\mathrm{AASM}_{2007 \mathrm{Rec}}$ classification $(\mathrm{P}<0.05$; Table 3).

\section{Multiple linear regression analysis}

A stepwise multiple linear regression analysis was performed to investigate predictors of differences in the AHI (2012 vs. $2007 \mathrm{Alt}, 2012$ vs. $2007 \mathrm{Rec}$ ) entering age, gender, BMI, severity of COPD (Table 4). The regression model $(\mathrm{F}=13.199, \mathrm{P}<0.001)$ showed that about $58 \%$ of the variation between AHI2012 and AHI 2007Alt $\left(\mathrm{R}^{2}=0.577, \mathrm{P}<0.001\right)$ was explained by the $\mathrm{BMI}(\mathrm{P}=0.001)$, gender $(\mathrm{P}=0.008)$ and severity of COPD $(\mathrm{P}=0.016)$. About $33 \%$ of the variation between the AHI2012 and AHI2007Rec $\left(\mathrm{R}^{2}=0.330, \mathrm{P}<0.05\right)$ was associated with BMI $(\mathrm{P}=0.013)$ and gender $(\mathrm{P}=0.024)$ $(\mathrm{F}=7.382, \mathrm{P}<0.05)$.

\section{Chinese and UK cobort}

For patients with COPD from the UK, the AHI using
$\mathrm{AASM}_{2007 \mathrm{Alt}}$ criteria was significantly lower than when using $\mathrm{AASM}_{2007 \mathrm{Rec}}$ criteria $[4.8$ events/hour $(1.8,10.7)$ vs. 12.8 events/hour $(5.8,15.5), \mathrm{P}<0.001]$. Using the $\mathrm{AASM}_{2007 \mathrm{Alt}}$ classification, the percentage of the British cohort that would not have been diagnosed as COPD/OSA overlap syndrome (AHI $\geq 5$ events/hour) was $38 \%$ while this was true for $25 \%(\mathrm{P}=0.5)$ using the $\mathrm{AASM}_{2007 R e c}$ classification. In contrast to the British cohort, the AHI in the Chinese cohort using $\mathrm{AASM}_{2007 \mathrm{Alt}}$ criteria was significantly higher than when using $\mathrm{AASM}_{2007 \mathrm{Rec}}$ criteria [30.2 events/hour (21.9, 42.2) vs. 18.2 events/hour $(17.1,37.8), \mathrm{P}<0.001]$. Using the $\mathrm{AASM}_{2007 \mathrm{Alt}}$ classification, the percentage of the Chinese cohort that would not have been diagnosed as COPD/OSA overlap syndrome (AHI $\geq 5$ events/hour) was significantly lower than when using the $\mathrm{AASM}_{2007 \mathrm{Rec}}$ classification ( $4 \%$ vs. $54 \%, \mathrm{P}<0.001)$.

\section{Discussion}

The introduction of the $\mathrm{AASM}_{2012}$ scoring rules resulted in a significantly higher AHI compared to the $\mathrm{AASM}_{2007}$ criteria in patients with COPD/OSA overlap syndrome. This was 
largely due to an increased number of arousal-associated hypopnoeas, and a significantly larger proportion of patients diagnosed with OSA when compared to $\mathrm{AASM}_{2007 \mathrm{Rec}}$ rather than $\mathrm{AASM}_{2007 \mathrm{Alt}}$. In contrast to the overall trend the increase in the AHI and the proportion of patients diagnosed with OSA in the British cohort using the 2012 AASM criteria was when compared to $\mathrm{AASM}_{2007 \mathrm{Alt}}$, rather than $\mathrm{AASM}_{2007 \mathrm{Rec}}$. To the best knowledge of the authors, this is the first study to investigate the impact of the 2007 and 2012 AASM scoring criteria on the AHI in COPD/OSA overlap syndrome.

\section{Clinical significance of findings}

Previous studies have focused on the difference between $\mathrm{AASM}_{2007 \mathrm{Alt}}, \mathrm{AASM}_{2007 \mathrm{Rec}}$, and $\mathrm{AASM}_{2012}$ in the general population and OSA, but not in patients with $\operatorname{COPD}(9,10)$. They found that implementation of the 2012 AASM criteria increased the AHI and the diagnosis of OSA. However, the effect of the rule changes on the hypopnoea index in our study in COPD/OSA overlap syndrome differs to previous studies. The study of Duce et al. demonstrated that the inclusion of EEG arousals contributed almost equally to the change in the hypopnoea index as the decrease in $\mathrm{SpO}_{2}$ desaturation requirement (9). In our study, the contribution of EEG arousal was significantly larger than that of the decrease in $\mathrm{SpO}_{2}$ desaturation (92\% vs. 8\%) in COPD/OSA overlap syndrome. Bonnet et al. and Guilleminault et al. found that arousals are common in the elderly (12) and absence of $\mathrm{SpO}_{2}$ desaturation often occurs in lean OSA patients (13). Hence, these differences between our results and others may be partially explained by the characteristics of our cohort, with elderly and leaner patients.

The studies of Marin et al. and Weitzenblum et al. demonstrate that patients with the overlap syndrome who suffer from more severe hypoxaemia and hypercapnia, may have a worse prognosis and higher mortality compared to patients with either condition alone $(14,15)$. However, there are conflicting data about the association of oxygen desaturations $(16,17)$ and clinically important outcomes $(18,19)$ in the COPD/OSA overlap syndrome. Soler's and our previous studies showed that the prevalence of oxygen desaturations was similar between patients with isolated COPD and patients with overlap syndrome $(16,17)$. Moreover, the clinical outcomes in patients on home mechanical ventilation for chronic respiratory failure is better in overlap syndrome compared to COPD alone in a recent report $(18,19)$, with no difference in mortality $(20)$.
This observation may be attributable to several factors. Different pathophysiological changes due to various phenotypes of overlap syndrome were reported in some studies (16). The change in the definition of hypopnoea by the $\mathrm{AASM}_{2012}$ criteria (7) could also result in an increased prevalence of overlap syndrome with predominant hypopnoea associated with arousals rather than severe desaturations, in particular for COPD patients according to the results of this study. Arousals are common in the elderly (12) which is a typical characteristic of patients with COPD. Moreover, a decrease of neural respiratory drive of COPD patients increases the chance of occurrence of hypopnoeas and hypoventilation $(16,21)$. Thus, we believe that COPD patients have many hypopnoeas that are distinct from other nocturnal respiratory events caused by a collapsible upper airway in OSA, especially when hypopnoeas are scored based on a flow reduction accompanied by an arousal. In a study by Du et al., OSA did not significantly impact on the mortality of patients with COPD (20). A recent cohort study suggested that COPD/OSA overlap syndrome is associated with a better prognosis than COPD alone $(18,19)$. Hence, we should be careful to diagnose COPD/OSA overlap syndrome and treatment implications.

Although these were small cohorts, there was an inverse trend in the Chinese and British cohorts between $\mathrm{AASM}_{2007 \mathrm{Rec}}$ and AASM $\mathrm{A}_{2007 \mathrm{Alt}}$. Our study demonstrated that the AHI using AASM $_{2007 \mathrm{Alt}}$ criteria was significantly lower than when using $\mathrm{AASM}_{2007 \mathrm{Rec}}$ criteria in the Chinese cohort, but significantly higher in the British cohort. In other words, the hypopnoeas that occurred in the British cohort were mostly associated with desaturations rather than arousals. This difference might be explained by different phenotypes of COPD, such as pink puffers or blue bloaters $(22,23)$. COPD patients with lower daytime $\mathrm{SpO}_{2}$ are also more likely to experience more severe nocturnal desaturations (24). In our study, the British cohort was more represented by "blue bloaters" with higher BMI and lower daytime $\mathrm{SpO}_{2}$ but also more preserved $\mathrm{FEV}_{1}$ than the Chinese cohort, which included more "pink puffers".

\section{Limitations}

This study represented a small sample, in particular of any comparison between Chinese and British patients. Although we selected patients with COPD/OSA overlap syndrome diagnosed by the criteria using an "AHI $\geq 5$ events/hour", there were limited subjects who were eligible for this study. The requirement of full PSG including the EEG signal 
could be the main reason. Portable sleep monitors without EEG signal might be easier to use in the general population and in COPD patients to diagnose and assess patients with COPD/OSA overlap syndrome. Notwithstanding the above limitations, our study demonstrated that there was a clear effect of the new classification on the diagnosis of COPD/ OSA overlap syndrome.

\section{Conclusions}

In summary, this study has demonstrated that the use of the $\mathrm{AASM}_{2012}$ scoring rules results in a significantly higher AHI compared to the $\mathrm{AASM}_{2007}$ criteria in patients with COPD/ OSA overlap syndrome. The increase of hypopnoeas in patients with COPD/OSA overlap syndrome is mostly associated with arousals rather than desaturations. These findings should be considered in diagnosing COPD/OSA overlap syndrome and treatment decisions in these patients.

\section{Acknowledgments}

We gratefully acknowledge the support of the clinical team at the Lane Fox Unit and the Sleep Disorders Centre at Guy's, St Thomas' NHS Foundation Trust, London and Key National Laboratory for Respiratory Disease, Guangzhou Medical University, China.

Funding: This project was funded by National Key R\&D Program of China (Grant Number: 2016YFC1304200) and National Natural Science Foundation of China (NSFC No. 81600064).

\section{Footnote}

Provenance and Peer Review: This article was commissioned by the Guest Editor (Joerg Steier) for the series "5th Clinical Update Sleep" published in Fournal of Thoracic Disease. The article was sent for external peer review organized by the Guest Editor and the editorial office.

Reporting Checklist: The authors have completed the STROBE reporting checklist. Available at http://dx.doi. org/10.21037/jtd-cus-2020-008

Data Sharing Statement: Available at http://dx.doi. org/10.21037/jtd-cus-2020-008

Conflicts of Interest: All authors have completed the ICMJE uniform disclosure form (available at http://dx.doi. org/10.21037/jtd-cus-2020-008). The series "5th Clinical Update Sleep" was commissioned by the editorial office without any funding or sponsorship. JS served as the unpaid Guest Editor of the series and serves as an unpaid editorial board member of Fournal of Thoracic Disease. JS's contribution was partially supported by the National Institute for Health Research (NIHR) Biomedical Research Centre based at Guy's and St Thomas' NHS Foundation Trust and King's College London. The authors have no other conflicts of interest to declare.

Ethical Statement: The authors are accountable for all aspects of the work in ensuring that questions related to the accuracy or integrity of any part of the work are appropriately investigated and resolved. This retrospective study was conducted in accordance with the Declaration of Helsinki (as revised in 2013) and was approved by the local review board at Guy's \& St Thomas' NHS Foundation Trust, King's College London and the First Affiliated Hospital of Guangzhou Medical University (the registered service review: 2019/9662). The requirement for informed consent was waived because of the retrospective study design applying to subsequent patients that fulfilled the review criteria.

Open Access Statement: This is an Open Access article distributed in accordance with the Creative Commons Attribution-NonCommercial-NoDerivs 4.0 International License (CC BY-NC-ND 4.0), which permits the noncommercial replication and distribution of the article with the strict proviso that no changes or edits are made and the original work is properly cited (including links to both the formal publication through the relevant DOI and the license). See: https://creativecommons.org/licenses/by-nc-nd/4.0/.

\section{References}

1. Young T, Palta M, Dempsey J, et al. The Occurrence of Sleep-Disordered Breathing among Middle-Aged Adults. N Engl J Med 1993;328:1230-5.

2. Young T, Peppard PE, Gottlieb DJ. Epidemiology of obstructive sleep apnea: a population health perspective. Am J Respir Crit Care Med 2002;165:1217-39.

3. WH. O. Burden of COPD 2019. Available from: https:// www.who.int/respiratory/copd/burden/en/

4. Flenley DC. Sleep in chronic obstructive lung disease. Clin Chest Med 1985;6:651-61.

5. Sanders MH, Newman AB, Haggerty CL, et al. Sleep and 
sleep-disordered breathing in adults with predominantly mild obstructive airway disease. Am J Respir Crit Care Med 2003;167:7-14.

6. Park JG, Ramar K, Olson EJ. Updates on definition, consequences, and management of obstructive sleep apnea. Mayo Clin Proc 2011;86:549-54; quiz 54-5.

7. Berry RB, Budhiraja R, Gottlieb DJ, et al. Rules for scoring respiratory events in sleep: update of the 2007 AASM Manual for the Scoring of Sleep and Associated Events. Deliberations of the Sleep Apnea Definitions Task Force of the American Academy of Sleep Medicine. J Clin Sleep Med 2012;8:597-619.

8. Iber C, American Academy of Sleep M. The AASM manual for the scoring of sleep and associated events: rules, terminology and technical specifications. Westchester, IL: American Academy of Sleep Medicine, 2007.

9. Duce B, Milosavljevic J, Hukins C. The 2012 AASM Respiratory Event Criteria Increase the Incidence of Hypopneas in an Adult Sleep Center Population. J Clin Sleep Med 2015;11:1425-31.

10. BaHammam AS, Obeidat A, Barataman K, et al. A comparison between the AASM 2012 and 2007 definitions for detecting hypopnea. Sleep Breath 2014;18:767-73.

11. Hirotsu C, Haba-Rubio J, Andries D, et al. Effect of Three Hypopnea Scoring Criteria on OSA Prevalence and Associated Comorbidities in the General Population. J Clin Sleep Med 2019;15:183-94.

12. Bonnet MH, Arand DL. EEG arousal norms by age. J Clin Sleep Med 2007;3:271-4.

13. Guilleminault C, Hagen CC, Huynh NT. Comparison of hypopnea definitions in lean patients with known obstructive sleep apnea hypopnea syndrome (OSAHS). Sleep Breath 2009;13:341-7.

14. Marin JM, Soriano JB, Carrizo SJ, et al. Outcomes in patients with chronic obstructive pulmonary disease and obstructive sleep apnea: the overlap syndrome. Am J

Cite this article as: $\mathrm{He} \mathrm{B}, \mathrm{Al}$-Sherif $\mathrm{M}, \mathrm{Wu} \mathrm{Y}$, Higgins $\mathrm{S}$, Schwarz EI, Luo Y, Said AF, Refat N, Abdel Wahab NH, Steier J. Apnoea-hypopnoea-index comparing the 2007 and 2012 American Academy of Sleep Medicine criteria in COPD/ obstructive sleep apnoea overlap syndrome. J Thorac Dis 2020;12(Suppl 2):S112-S119. doi: 10.21037/jtd-cus-2020-008
Respir Crit Care Med 2010;182:325-31.

15. Weitzenblum E, Chaouat A, Kessler R, et al. Overlap syndrome: obstructive sleep apnea in patients with chronic obstructive pulmonary disease. Proc Am Thorac Soc 2008;5:237-41.

16. He BT, Lu G, Xiao SC, et al. Coexistence of OSA may compensate for sleep related reduction in neural respiratory drive in patients with COPD. Thorax 2017;72:256-62.

17. Soler X, Gaio E, Powell FL, et al. High Prevalence of Obstructive Sleep Apnea in Patients with Moderate to Severe Chronic Obstructive Pulmonary Disease. Ann Am Thorac Soc 2015;12:1219-25.

18. Patout M, Ramsay M, Mackie M, et al. Home mechanical ventilation (HMV): Setup and outcome in Europe. Eur Respir J 2015;46:OA4780.

19. Schwarz EI, Mackie M, Weston N, et al. Time-todeath in chronic respiratory failure on home mechanical ventilation: A cohort study. Respir Med 2020;162:105877.

20. Du W, Liu J, Zhou J, et al. Obstructive sleep apnea, COPD, the overlap syndrome, and mortality: results from the 2005-2008 National Health and Nutrition Examination Survey. Int J Chron Obstruct Pulmon Dis 2018;13:665-74.

21. Luo YM, He BT, Wu YX, et al. Neural respiratory drive and ventilation in patients with chronic obstructive pulmonary disease during sleep. Am J Respir Crit Care Med 2014;190:227-9.

22. Burgel PR, Sethi S, Kim V. Chronic obstructive pulmonary disease phenotypes. Past, present, and future. Ann Am Thorac Soc 2015;12:289-90.

23. Dornhorst AC. Respiratory insufficiency. Lancet 1955;268:1185-7.

24. Lewis CA, Fergusson W, Eaton T, et al. Isolated nocturnal desaturation in COPD: prevalence and impact on quality of life and sleep. Thorax 2009;64:133-8. 